\title{
A COMBINATION OF PATHOLOGIES - FACET JOINT SYNOVIAL CYST, EPIDURAL LIPOMATOSIS AND CONJOINED NERVE ROOT ANOMALY IN THE LUMBAR SPINE OF A 45-YEAR-OLD PATIENT. A CASE REPORT
}

\author{
Elena Harizanova ${ }^{1,2}$, Yavor Enchev ${ }^{3,4}$, Bogomil Iliev ${ }^{3,4}$ \\ ${ }^{1}$ Department of Anatomy and Cell Biology, Faculty of Medicine, \\ Medical University of Varna \\ ${ }^{2}$ Department of Neurosurgery, St. Anna Hospital, Varna \\ ${ }^{3}$ Department of Neurosurgery and ENT, Faculty of Medicine, Medical University of Varna \\ ${ }^{4}$ Department of Neurosurgery, St. Marina University Hospital, Varna
}

\begin{abstract}
Facet joint synovial cysts are abnormal fluid-filled cystic formations that develop from a degenerative process of the facet joints. Spinal epidural lipomatosis is a process of excessive accumulation of fat in the epidural space. Conjoined nerve root (CNR) anomaly refers to an anatomical variation in which two adjacent nerve roots share a common dural sleeve. The aforementioned three rare pathologies cause the same pathological process of stenosis, therefore compressing the nervous structures.
\end{abstract}

A 45-year-old female patient was admitted to the Department of Neurosurgery with severe low back and radicular pain, and numbness along her left leg. Antalgic posture, painful paravertebral muscle tenderness, $\mathrm{L} 4$ radiculopathy, and $\mathrm{L} 5$ and $\mathrm{S1}$ dermatome hypoesthesia on the left as well as positive straight leg raising sign (Laseque) were present upon examination. CT and MRI scanning showed stenosis on L4-L5 level caused by bilateral synovial cyst formation.

Microsurgical decompression by foraminotomy at L4-L5 level on the left with dissection of the synovial cyst and epidural lipomatosis was performed. In the course of the operation CNR anomaly was discovered. The complete decompression alleviated the symptoms and after 3 uneventful postoperative days the patient was discharged.

Spinal stenosis causing compression upon nervous structures is a process that could be caused by a number of conditions. The incidence of rare pathologies and anomalies or even the more rarely occurring combination of them must be considered on daily basis in the clinical practice in order to make the correct

Address for correspondence:

Elena Harizanova

Department of Anatomy and Cell Biology

Faculty of Medicine

Medical University of Varna

55 Marin Drinov

9002 Varna

Bulgaria

e-mail:elena.d.harizanova@gmail.com

Received: August 19, 2019

Accepted: December 23, 2019 diagnosis and plan the best possible treatment for the patient.

Keywords: neurosurgery, spinal stenosis, facet joint synovial cyst, epidural lipomatosis, conjoined nerve root anomaly, duplication of nerve root 


\section{INTRODUCTION}

Facet joint synovial cysts are abnormal fluidfilled cystic formations that develop from the degenerative process of the facet joints $(1,2)$. The reported incidence of these lesions in magnetic resonance imaging (MRI) and computed tomography (CT) scanning varies in the different groups and imaging modalities with the highest prevalence in symptomatic population reported by Doyle and Merilees - 2.3\% for anterior and $7.3 \%$ for posterior cysts $(3,4,5,6)$. The symptomatic patients are usually in their sixties and present with low back pain, unilateral radicular pain, and neurogenic claudication, with much rarer incidence of motor and sensory disturbance $(6,7,8)$.

Spinal epidural lipomatosis is a process of abnormal excessive accumulation of fat in the epidural space, which leads to narrowing of the spinal canal and compression of the nervous structures. The mean age of patients is $69.4 \pm 10.9$ years and the usual manifestation in the symptomatic population is low back pain, myelopathy or radiculopathy due to compression at different spinal levels $(9,10,11)$.

The term conjoined nerve root (CNR) anomaly refers to an anatomical variation in which two adjacent nerve roots share a common dural sleeve at some point in their course before separating to follow individual courses through the same or separate foramina. On its own in normal conditions the CNR anomaly is usually asymptomatic. However, due to overcrowding of the nerve canal, compression of different origin may lead to radiculopathy, neurogenic claudication and neurological deficit $(12,13,14)$.

\section{CASE PRESENTATION}

A 45-year-old female patient was complaining of low back, radicular pain and numbness along her left leg that were gradually intensifying to a severe level for few weeks prior to admission to the Department of Neurosurgery. Upon examination antalgic posture and gait were prominent. Paravertebral muscle tenderness and painful trigger points in the lumbar spine were present as well as L4 radiculopathy and L5 and S1 dermatome hypoesthesia for the left leg. On the same side, the straight leg raising sign (Laseque) was positive with maximum height of 20 degrees. As the laboratory test results were normal, the imaging was essential. First a CT scan was performed and it showed degenerative changes in the lumbar spine with central stenosis on L4-L5 level - $14 \mathrm{~mm}$, and L5-S1 - $8 \mathrm{~mm}$ (minimum normal width of the vertebral canal in the lumbar region - $15 \mathrm{~mm}$ ). In addition to that, a lesion causing lateral recess and foraminal stenosis was visible at L4- L5 level on the left (Fig. 1).

As an imaging modality with better visualization of the tissues, an MRI scan was performed in order to aid the correct identification of the pathology of our patient. It showed bulging of the intervertebral disks at L4-L5 and L5-S1 spinal levels and spondyloarthrosis of the facet joints at L4-L5 level with formation of bilateral synovial cysts resulting in central stenosis of the spinal canal (12.7 $\mathrm{mm}$ sagittal length), left lateral recess narrowing, and bilateral foraminal stenosis. In addition to that, anterior spondylolisthe-
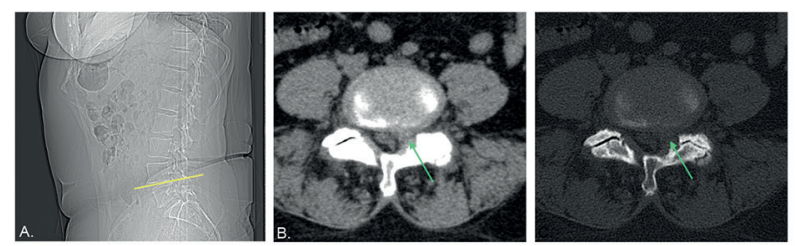

Fig. 1. Preoperative CT scan. A. Topogram, yellow line marks L4-L5 level of the spine. B. Axial soft tissue window image at L4-L5 level. C. Bone window image at L4L5 level. The green arrow on $\mathbf{B}$. and $\mathbf{C}$. shows a pathological lesion that causes stenosis of the left lateral recess and left intervertebral foramen
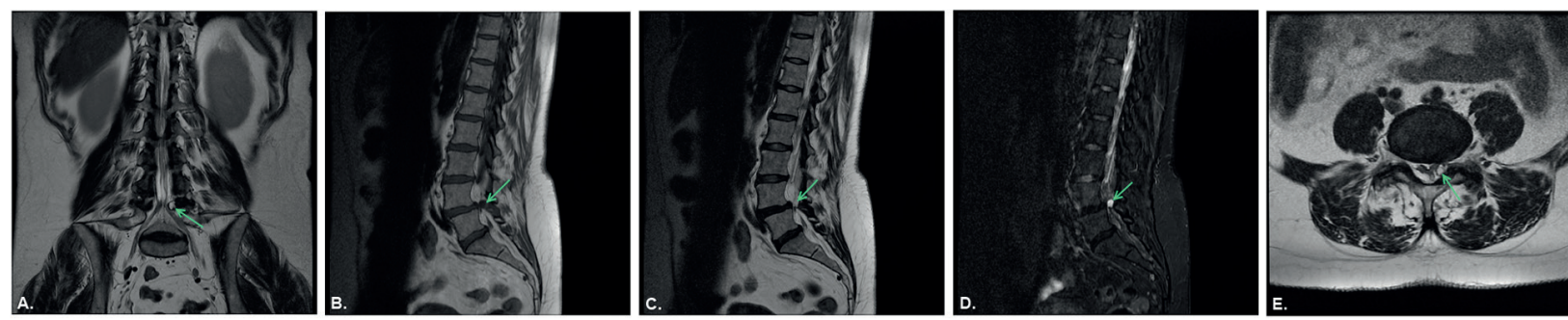

Fig. 2. Preoperative MRI scan. A. T2 coronal section, B. T1 sagittal section, C. T2 sagittal section, D. STIR sagittal section, E. T2 axial section. At L4-L5 and L5-S1 spine levels there are building of the intervertebral discs. A synovial cyst at L4-L5 level on the left is marked by a green arrow on all images

Scripta Scientifica Medica, 2019;51(4):26-30

Medical University of Varna 
A Combination of Pathologies - Facet Joint Synovial Cyst, Epidural Lipomatosis and Conjoined Nerve Root Anomaly in the Lumbar Spine...
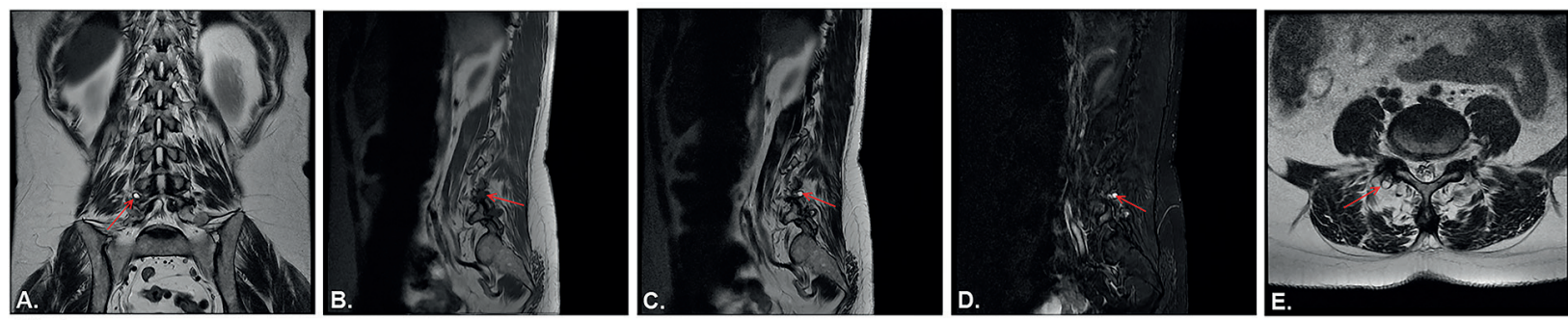

Fig. 3. Preoperative MRI scan. A. T2 coronal section, B. T1 sagittal section, C. T2 sagittal section, D. STIR sagittal section, E. T2 axial section. At L4-L5 and L5-S1 spine levels there is building of the intervertebral discs. A synovial cyst at L4-L5 level on the right is marked by a red arrow on all images

sis at L4-L5 vertebral level was also present (Fig. 2), (Fig. 3).

The medical history of the patient, the physical examination and the imaging results pointed to a diagnosis of spinal stenosis and nerve root compression in the lumbar region on the left due to facet joint synovial cyst formation. After careful reviewing of the case and all of its aspects, a decision for surgical treatment was made in order to alleviate the neurological symptoms.

The surgical procedure started with assessment of the correct vertebral level using a mobile Ziehm Vision FD Vario 3D C-arm X-ray system, followed by linear incision from L4 to L5 level. After dissection of the left paravertebral muscles using Zeiss OPMI PENTERO 900 surgical microscope under optical magnification, a left foraminotomy at L4-L5 level was performed. Compression of the dural sac by the synovial cyst on the left and epidural lipomatosis were prominent. In the course of dissection of the formations, an anatomical variation of duplication of L5 nerve root was discovered. Complete decompression of the nervous structures was performed by ex-

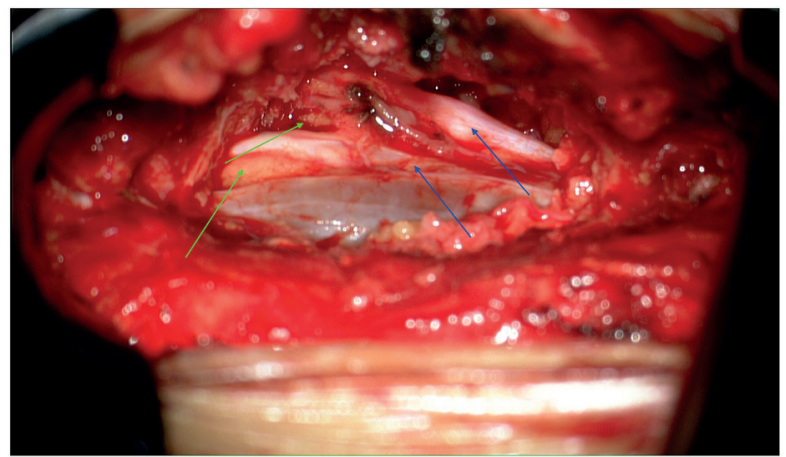

Fig. 4. Intraoperative image from Zeiss OPMI PENTERO 900 Surgical Microscope showing a synovial cyst (blue arrow)

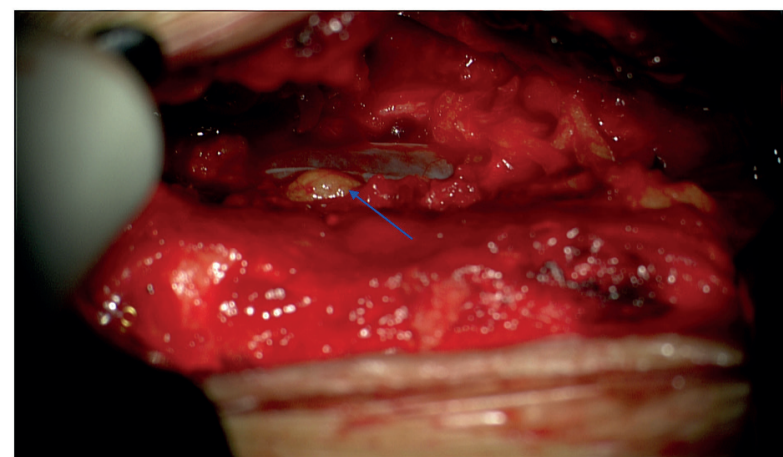

Fig. 5. Intraoperative image from Zeiss OPMI PENTERO 900 Surgical Microscope showing double root anomaly

(blue arrows) and epidural lipomatosis (green arrow)

cision of the synovial cyst and the epidural lipomatosis. In addition, INCERT-S anti-adhesion gel was applied (Fig. 4), (Fig. 5).

\section{RESULTS}

The surgical procedure done in the Department of Neurosurgery - total excision of both the synovial cyst and the epidural lipomatosis, allowed complete decompression of the nervous structures. The identification of the duplicated L5 nerve root did not change the course of the planned intervention as the left foraminotomy and the careful dissection of the pathological formations provided decompression of the two roots in the stenosed left foraminal canal as well. In addition to that, the resected material was sent for histological verification of the clinical diagnosis of facet joint synovial cyst. After uneventful postoperative period of 3 days, the patient was discharged with improvement of the neurological symptoms.

\section{DISCUSSION}

The first point that deserves attention in this case is the presence of epidural lipomatosis. This 
pathology is believed to develop either when there is hormonal disturbance with corticosteroid therapy, endocrine disorders and obesity or idiopathically $(10,17,18)$. As it is a rare pathology with incidence of symptomatic cases reported in only $0.1 \%$ of all the patients with low back pain, there are no clinical trials assessing the results after conservative and surgical treatment $(10,11)$. Conservative measures, such as termination of corticosteroid therapy, reduction of weight, and treatment for endocrine disorders can be implemented when the etiology of elevated hormonal levels is suspected. For idiopathic cases, such as our patient, surgical decompressive laminectomy and resection of the fat tissue is the treatment of choice $(10,18)$.

Another aspect of this case is the diagnosis of facet joint synovial cyst. As it was mentioned in the introduction, this pathology is a rare cause of symptomatic spinal compression. Because of the similarity of the clinical manifestation of facet joint synovial cysts to that of other vertebral degenerative pathologies causing compression of the nervous structures, it is important for the clinician to consider this lesion in the differential diagnosis $(6,8)$. A meta-analysis comparing the operative treatment methods for facet joint synovial cysts (percutaneous aspiration and surgical decompression with or without fusion) in 870 patients in 50 studies was performed in a study last year. The results showed full resolution of the symptoms in the percutaneous group in 58\% compared to $90 \%$ in the decompression one. In addition to that, $29 \%$ in the percutaneous group underwent more than 1 aspiration and 38\% were indicated for surgery in the follow-up period (19). This study and its results are comparable to other sources and published clinical experience so that decompressive surgical approach is recommended as a treatment with best possible outcome for the patients $(6,8)$. The question about spinal stability in patients with facet joint cysts remains disputable though. In a number of studies, the combination of synovial cysts and preoperative spondylolisthesis suggests instability. In these cases, it is recommended that patients underwent decompression and fusion surgery than decompression alone or these patients would probably require additional fusion surgery after the initial decompressive one (20). In our patient, spondylolisthesis was also present but due to the lateral localization of the cyst with lateral recess and foraminal stenosis, the surgical approach was decompression by foraminotomy as in this way the spinal stability would not be compromised.

In our case, attention should also be paid to the presence of double root anatomical variation. Conjoined nerve root anomalies tend to be asymptomatic until a coexisting pathology causes compression of the already narrowed by the duplicated root lateral recess and foramen. The clinical manifestation of CNR is similar to that of the causative lesion and so the underlying pathology is not usually addressed. Without adequate decompression by foraminotomy in addition to the laminectomy, the stenosis and subsequently the symptoms are not relieved. In such cases, an undiagnosed CNR can be considered as a possible cause for failed spinal surgery $(13,14,21)$. As it is said, when it comes to women age is an important issue. Reviewing the literature it appears that facet joint synovial cysts and epidural lipomatosis as diagnosis of symptomatic compression of the spinal cord usually present in patients in their $50 \mathrm{~s}, 60 \mathrm{~s}$ and older $(2,3,9,11)$. This late onset might be related to the degeneration process of the vertebral column as possible pathogenesis of these lesions $(3,8,14)$. Nonetheless our patient is 15 years younger than the usual occurrence period and the fact that she has a combination of three pathologies, two that cause stenosis - facet synovial cyst and epidural lipomatosis, and a double root anomaly that narrows the lateral recess and the intervertebral foramen seems too much of a coincidence to be ignored.

\section{CONCLUSION}

We presented you a case with a combination of three rare conditions that cause the same pathophysiological process - stenosis with typical manifestation in our patient. This case was reported in order to show that a careful evaluation of the symptoms and their possible causative pathologies should always be done. The good physician should have a wide range of differential diagnoses as well as think about the mechanism, which caused the given condition. The incidence of rare conditions, anomalies, combination of pathologies and, as in our case, combination of rare pathologies and anomalies should not stay just in the books or articles, but must be considered on a daily basis in the clinical practice in order 
A Combination of Pathologies - Facet Joint Synovial Cyst, Epidural Lipomatosis and Conjoined Nerve Root Anomaly in the Lumbar Spine...

to make correct diagnosis and plan the best possible treatment for the patient.

\section{REFERENCES}

1. Ross J, Moore K. Diagnosic Imaging: Spine. $3^{\text {rd }}$ ed. Elsevier; 2015.

2. Niosi CA, Oxland TR. Degenerative mechanics of the lumbar spine. Spine J.2004; 4(6 Suppl): 202S208S. doi: 10.1016/j.spinee.2004.07.013.

3. Doyle AJ, Merrilees M. Synovial cysts of the lumbar facet joints in a symptomatic population: prevalence on magnetic resonance imaging. Spine (Phila Pa 1976). 2004; 29(8):874-8. doi: 10.1097/00007632-200404150-00010.

4. Eyster EF, Scott WR. Lumbar synovial cysts: report of eleven cases. Neurosurgery. 1989; 24(1):112-5. doi: 10.1227/00006123-198901000-00021.

5. Lemish W, Apsimon T, Chakera T. Lumbar intraspinal synovial cysts. Recognition and CT diagnosis. Spine. 1989; 14.12:1378-83. doi: 10.1097/00007632-198912000-00016.

6. Hohenberger C, Brawanski A, Ullrich OW, Höhne J, Zeman F, Schebesch KM. Degenerative symptomatic spinal synovial cysts: Clinical presentation and functional outcome. J Clin Neurosci. 2019;62:112-116. doi: 10.1016/j.jocn.2018.12.006.

7. Métellus P, Fuentes S, Adetchessi T, Levrier O, Flores-Parra I, Talianu D, et al. Retrospective study of 77 patients harbouring lumbar synovial cysts: functional and neurological outcome. Acta Neurochir (Wien). 2006; 148(1):47-54. doi: 10.1007/ s00701-005-0650-z.

8. Lyons MK, Atkinson JL, Wharen RE, Deen HG, Zimmerman RS, Lemens SM. Surgical evaluation and management of lumbar synovial cysts: the Mayo Clinic experience. J Neurosurg. 2000; 93(1 Suppl):53-7. doi: 10.3171/spi.2000.93.1.0053.

9. Park SK, Han JM, Lee K., Cho WJ, Oh JH, Choi YS. The clinical characteristics of spinal epidural lipomatosis in the lumbar spine. Anesth Pain Med. 2018; 8(5):e83069. doi: 10.5812/aapm.83069.

10. Fassett D, Schmidt M. Spinal epidural lipomatosis: a review of its causes and recommendations for treatment. Neurosurg Focus. 2004; 16(4):E11.

11. Theyskens NC, Paulino Pereira NR, Janssen SJ,Bono CM,Schwab JH, Cha TD. The prevalence of spinalepidural lipomatosis on magnetic resonance imaging. Spine J. 2017; 17(7):969-76. doi: 10.1016/j.spinee.2017.02.010.
12. Kadish LJ, Simmons EH. Anomalies of the lumbosacral nerve roots. An anatomical investigation and myelographic study. J Bone Joint Surg Br. 1984; 66(3):411-6.

13. Schmidt CK, Rustagi T, Alonso F, Loukas M, Chapman JR, Oskouian RJ, et al. Nerve root anomalies: making sense of a complicated literature. Childs Nerv Syst. 2017; 33(8):1261-73. doi: 10.1007/ s00381-017-3457-3.

14. Lotan R, Al-Rashdi A, Yee A, Finkelstein J. Clinical features of conjoined lumbosacral nerve roots versus lumbar intervertebral disc herniations. Eur Spine J. 20101; 19(7):1094-8. doi: 10.1007/ s00586-010-1329-6.

15. Boviatsis E, Staurinou L, Kouyialis A, Gavra M, Stavrinou P, Themistokleous M, et al. Spinal synovial cysts: pathogenesis, diagnosis and surgical treatment in a series of seven cases and literature review. Eur Spine J. 2008; 17(6):831-7. doi: 10.1007/ s00586-007-0563-z.

16. Guegan Y, Fardoun R, Launois B, Pecker J. Spinal cord compression by extradural fat after prolonged corticosteroid therapy. J Neurosurg. 1982 Feb; 56(2):267-9. doi: 10.3171/jns.1982.56.2.0267.

17. Robertson SC, Traynelis VC, Follett KA,Menezes AH. Idiopathic spinalepidurallipomatosis. Neurosurgery.1997; 41(1):68-74. doi: 10.1097/00006123-199707000-00015.

18. Campbell RJ, Mobbs RJ, Rao P, Phan K. Interventions for lumbar synovial facet joint cysts: a comparison of percutaneous, surgical decompression and fusion approaches. World Neurosurg. 2017; 98:492-502. doi: 10.1016/j.wneu.2016.11.044.

19. Ramhmdani $S$, Ishida W, Perdomo-Pantoja A, Witham TF, Lo SL, Bydon A. Synovial cystas a marker for lumbar instability: a systematic review and meta-analysis. World Neurosurg. 2019;122:e1059-e1068. doi: 10.1016/j. wneu.2018.10.228.

20. Shaban AB, Atiyah Q, Ajaj SS. An intraoperative finding of double L5 nerve root. Ibnosina J Med Biomed Sci. 2017; 9:169-71.

21. Scuderi GJ,Vaccaro AR,Brusovanik GV, Kwon BK, Berta SC. Conjoined lumbar nerve roots: a frequently underappreciated congenital abnormality. J Spinal Disord Tech. 2004; 17(2):86-93. doi: 10.1097/00024720-200404000-00002. 